\title{
Formación Tecnológica y Responsabilidad Social Universitaria
}

Liliana Canquiz Rincón / Jorge Valarezo Castro Compiladores

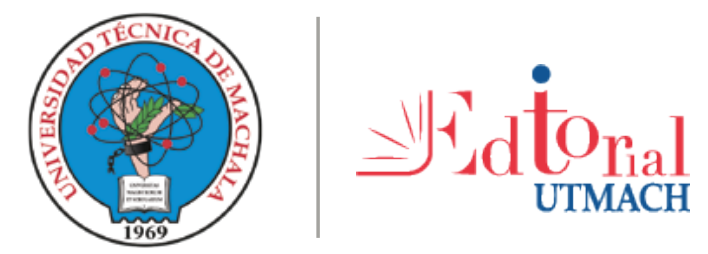


Ediciones UTMACH

189 pág: $21 \times 29,7 \mathrm{~cm}$

Colección Monográficos

Título: Formación Tecnológica y Responsabilidad Social universitaria - Liliana Canquiz Rizncón y Jorge Valarezo Castro

(Compiladores)

Primera edición 2020

ISBN: 978-9942-24-141-2

CDD 607

1. Enseñanza de la investigación,

2. Tecnologías de la información y la comunicación

--Temas relacionados

Publicación PDF 
Formación Tecnológica y Responsabilidad Social Universitaria

\section{Liliana Canquiz Rincón \\ Jorge Valarezo Castro \\ COMPILADORES}

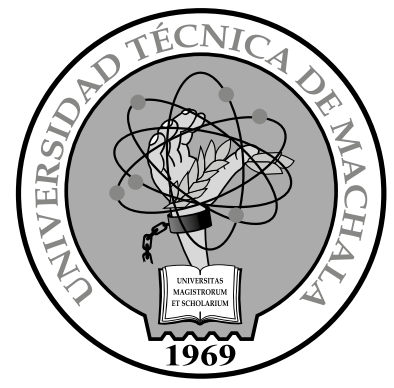




\section{Liliana Canquiz Rincón}

Postdoctorado y Doctorado en Ciencias Humanas, Magister en Educación. Mención: Planificación Educativa. Licenciada en Educación, Mención Ciencias Pedagógicas, Área Tecnología Instruccional de la Universidad del Zulia, Venezuela. Docente Investigadora de la Universidad de la Costa, Barranquilla-Colombia, Líder de la sublínea de investigación Currículo y Procesos Pedagógicos. Con mas de 28 años de experiencia en docencia universitaria a nivel de pre y postgrado. Especialista en desarrollo curricular. Asesora editorial. Conferencista y ponente en eventos nacionales e internacionales. Autora de libros, capítulos de libros y artículos en revistas indexadas de alto impacto. Tutora y jurado de trabajos de grado a nivel de pre y posgrado. Investigadora Asociada categorizada por Colciencias (2018). 


\section{Autoridades}

César Quezada Abad - Rector Amarilis Borja Herrera - Vicerrector Académico Jhonny Pérez Rodríguez - Vicerrector Administrativo

Luis Brito Gaona Director de Investigación () Ediciones UTMACH Colección Monográficos

Título original: Formación Tecnológica y Responsabilidad Social Universitaria

ISBN: 978-9942-24-141-2

(c) Liliana Canquiz Rincón y Jorge Valarezo Castro

(Compiladores)

(c) Autores de capítulos

DOI: http://doi.org/10.48190/9789942241412

Primera edición 2020

Karina Lozano Zambrano Jefe editor / Diseño y edición editorial

Fernanda Tusa Jumbo - Corrector de estilos Jorge Maza-Cordova - Asesor tecnológico Karla Ibañez y Cyndi Aguilar - Equipo de difusión

Este obra está bajo una licencia de Creative Commons Reconocimiento No Comercial. Esta licencia permite a otros entremezclar, ajustar y construir a partir de su obra con fines no comerciales, siempre y cuando le reconozcan la autoría y sus nuevas creaciones estén bajo una licencia con los mismos términos. 
El redescubrimiento del periodismo literario desde la voz de sus protagonistas 
El redescubrimiento del periodismo literario desde la voz de sus protagonistas

\author{
Paula Moreno Sánchez \\ Fernanda Tusa Jumbo
}

Autores 


\section{El redescubrimiento del periodismo literario desde la voz de sus protagonistas}

\section{Paula Moreno Sánchez}

Licenciada en Comunicación Social por la Universidad Técnica de Machala. Miembro del Semillero de Investigación 'Acción Lectora'. Autoras de varios artículos científicos y ponente en congresos nacionales de literatura y comunicación. También tiene cursos de maquillaje para cámaras y fotografía.

\section{Fernanda Tusa Jumbo}

Doctora en Comunicación Social. Docente universitaria de las cátedras de Metodología de la Investigación II y Comunicación Académica de la Universidad Técnica de Machala. Miembro del Grupo de Investigación GIDCOWEB y docente tutora del Semillero Acción Lectora. Su línea de investigación es comunicación, literatura y tecnología.

DOI: http://doi.org/10.48190/9789942241412.8 


\section{Introducción}

Antiguamente, la formación académica de un comunicador se veía limitada a la preparación que se adquiría en las empresas de medios, misma que se instruía en base de actividades generales y poco especializadas, lo que brindaba un ejercicio profesional más empíricio de la comunicación. Esta realidad la describe perfectamente, situando su estudio en los medios impresos colombianos, García Márquez (1982) en su texto 'El mejor oficio del mundo'.

Si bien es cierto, el mundo se ha visto sometido a grandes cambios, y por ende también la sociedad. A día de hoy, el lector, el televidente, el radioescucha, o como queramos llamarlo, se ha convertido en un ente más exigente y crítico, lo que produce una reinvención en la propuesta tradicional de los medios, los cuales ahora deben generar mensajes creativos, atractivos y de debate social, que permitan tener una real conexión, de empatía, con la audiencia.

En ese sentido, Solís (2014) indica que "la escritura creativa operaría dentro del enfoque del lenguaje imaginativo en cuanto al empleo de la imaginación para la narración de hechos", lo que apoya la idea de una nueva formación en torno a la escritura creativa y la redacción literaria para la generación de contenidos mediáticos alternativos y transformadores.

En materia de periodismo literario y periodismo cultural, la producción de contenidos creativos no solo genera fidelización y atrae a las audiencias, sino que también le da al comunicador un espacio profesional más especializado, que supera el campo de los medios masivos de comunicación, pues esta nueva generación de periodistas crea propuestas en base de las nuevas tecnologías, produciendo reportajes, crónicas y perfiles, que incluso son convertidos, a posterior, en producciones audiovisuales.

El contexto detallado anteriormente sirve para presentar el tema de investigación: 'importancia de la escritura creativa y creación literaria, un redescubrimiento del periodismo literario desde la voz de sus protagonistas'. Al respecto, se plantea la siguiente problemática:

¿Es posible conciliar la literatura con el periodismo? ¿Por qué es necesario hablar de periodismo literario en la sociedad del Conocimiento? En este escenario el objetivo propuesto es:

- Determinar la importancia de la escritura creativa y la creación literaria para el ejercicio periodístico en la actualidad, a través de una serie de entrevistas a escritores, profesionales y docentes de Comunicación, a fin de valorar su perspectiva del tema-objeto de estudio.

La creación literaria y la escritura creativa son importantes campos dentro del área comunicacional, puesto que permiten ampliar los ejes de formación de un comunicador, creando así un profesional multifacético y especializado en redacción y cultura general. 
Actualmente, la versatilidad, la generación de contenido creativo y la comunicación van estrechamente unidas con el propósito de conquistar a nuevos públicos, vender historias más integrales y enriquecidas en su contexto. Por eso se justifica la pertinente de este tipo de investigaciones, lideradas desde la academia, por parte de un Semillero conformado por investigadores nóveles que trabajan en la línea 'Comunicación y Literatura'.

\section{Desarrollo conceptual}

\section{Lenguaje escrito}

De acuerdo con Intriago, Mieles, Murillo \& Flores (2017), "escribir, como leer, son habilidades que se van perfeccionando a lo largo de la vida pues durante la actividad de escribir el pensamiento construye un significado y lo manifiesta a través del lenguaje verbal escrito”.

Por su parte Rojas (2018) menciona que "leer y escribir son destrezas que sobrepasan las capacidades individuales y permiten una construcción que se refleja en la sociedad en la capacidad de las personas para desenvolverse y negociar sentidos en su cotidianidad”. Estos dos criterios evidencian que la escritura es atemporal y su importancia va más allá de una línea de tiempo; al contrario, interpelan los significados que los seres humanos construimos en sociedad, en lo cotidiano.

No en vano se advierte que el ejercicio asiduo de la escritura nos hace mejores seres humanos, puesto que quien lo practica a diario trabaja con sus sensibilidades y la realidad que construye del mundo. Intriago et al. (2017) considera que la comunicación escrita ofrece "una expresión más integral de las ideas del emisor, lo que requiere de una preparación previa que conduzca hacia su selección y ordenamiento lógico, entre otros aspectos”.

Esta última idea sirve para contextualizar la utilización de la escritura como componente esencial de cualquier profesión, más aún, de la comunicación. Y es que la habilidad lecto-escritora mejora la comprensión, así como la organización de las ideas y los argumentos.

Se precisa también desarrollar un buen estilo de escritura, una voz propia como autor, debido a que el mensaje escrito es la conexión directa para generar vínculos fidedignos con el público lector, en el caso de los medios impresos. Hablar de una escritura de calidad deriva en el buen entendimiento de los mensajes y en el hecho de generar un contracto tácito de lectura con la audiencia. 


\section{Comprensión lectora}

Para abordar el tema del periodismo literario se debe considerar los hábitos de lectura, ya que este es un principio básico que da paso a la escritura. No se trata únicamente de leer los textos, sino de saber interpretarlos y comprenderlos, lo que permita una correcta decodificación de los mensajes en medios impresos. En efecto, son los niveles de comprensión lectora los que condicionan el hecho de que el ser humano pueda asumir, o no, a la lectura como una de las mejores experiencias de disfrute intelectual.

Una de las principales causas de los niveles bajos de lectura es justamente la falta de interés del lector, misma que es provocada por procesos de lectura mecánica, que no aportan aprendizajes significativos en cuanto a conocimiento y reflexión. De esta manera, se genera una barrera que impide la adquisición de nuevos conocimientos en base de piezas textuales (Quezada \& Daniel, 2017), migrando los lectores al consumo mediático de imágenes y videos.

La importancia de la compresión lectora es indiscutible, esta es la base primordial si se busca ejercer un periodismo literario de interés social, que cautive a un público amplio. Por ello, es la apuesta del Estado por fomentar campañas de lectura, transversales al currículo.

En el caso de Ecuador, por citar un ejemplo, en los últimos años se ha establecido como política cultural la promoción de la lectoescritura en la Campaña de Lectura Eugenio Espejo y las ferias de libro en ciudades como Guayaquil y Quito (Campaña de Lectura, 2019).

\section{Importancia de la lectoescritura}

De acuerdo con Agar \& López (2018) "la lectoescritura es el medio que permite a las personas ser capaces de construir y desarrollar su conocimiento, además de transmitir y comunicar información”. Se logra entender entonces que la lectoescritura tiene una relación directa con la comunicación, debido a que auspicia la interrelación social a través del uso compartido de signos y códigos por hablantes de la misma lengua.

A criterio de Rojas (2018), "el ecosistema mediático actual es una red compleja de relatos y medios convergentes que está transformando las maneras de consumir, interactuar y producir contenidos, como los textos escritos”. Es una realidad la transformación acelerada del mundo en que vivimos condicionado por grandes cambios tecnológicos que inciden en las formas de consumo cultural y de gestión del ocio. Al respecto, la lectoescritura ya no se da únicamente en plataformas convencionales sino también en entornos digitales. Como afirman Secul Giusti \& Viñas (2016): 
(...) los procesos de lectura y escritura comenzaron a materializarse en tramas virtuales, de características propias y subjetividades usuarias. Se entiende así que las redes sociales potencian la lectura social porque facilitan el intercambio de opiniones, permiten el acceso a la intertextualidad, la interpretación de discursos, la proliferación de citas y la divulgación de fragmentos de obras, anotaciones y/o comentarios de la cultura. Del mismo modo, profundizan la relación entre los autores y sus lectores. (p.31)

Considerando entonces este gran cambio de paradigma cultural en la Sociedad de la Información nos preguntamos ¿Se debe auspiciar la lectoescritura en el ciberespacio? ¿cómo leer en la pantalla? ¿con la escritura colaborativa nos convertimos todos en autores?

Así surgen campañas de alfabetización mediática y digital para que los usuarios desarrollen ciertas competencias, habilidades y destrezas propias del mundo análogo, que les sean útiles para consumir y crear en red sus propios contenidos.

Las plataformas digitales están siendo aprovechadas por la Generación Millenial ya no solo como un espacio de consumo y entretenimiento, sino también como un escenario alternativo para la comunicación masiva, el periodismo ciudadano, la industria cultural, debido a que lo digital propone nuevas pautas profesionales y de gestión del talento, capaz de mostrar contenido innovador, dinámico e interactivo, con poco espacio de difusión en medios convencionales. Es decir, lo digital constituye un ecosistema que fomenta valores como libertad e innovación.

\section{Talleres literarios y de escritura creativa}

Una buena educación literaria es aquella que permita al estudiante apropiarse de los recursos estilísticos de su propio lenguaje y desarrollar su capacidad crítica ante la información que recibe, a fin de producir y comunicar ideas de forma correcta. Estas competencias resultan sumamente necesarias en momentos donde la información es muy amplia, volátil y de fácil acceso (López, Zermeño \& Galbraith, 2017).

La promoción de los hábitos de lectoescritura es un paso primordial dentro del proceso comunicativo. Ello se consigue además con la creación de talleres literarios y de escritura creativa. Tal y como describe López et al. (2017) "los talleres literarios son "espacios donde las personas organizan, crean, imaginan, proponen, estructuran ideas y las plasman a través de la escritura, por lo que permiten una intertextualidad, una acción de pasar de un texto a otro para obtener más textos”.

Según Juárez Morena (1997), con la puesta en común de los talleres "la literatura deja de ser un dominio de contenidos históricos, memorísticos y teóricos, para transformarse en un material con el que se trabaja y se usa, y que, a veces se llega a dominar". Se entiende entonces que estos talleres fomentan la producción literaria entre quienes lo practican de forma disciplinada, como un hábito y vocación de vida. Los talleres fomentan la producción nóvel, resignificando la producción 
literaria en el campo cultural nacional, teniendo como precursores a los talleristas, una generación joven de literatos en Ecuador.

La importancia de la creación de contenido se ha visto en su mayor auge en los últimos años, pues las audiencias se han convertido en un fenómeno con hambre de información, de conocimiento, e incluso de generación del mismo.

Por tanto, la tarea del comunicador de producir contenido se ha especializado hacia nuevos públicos con bae en la persuasión, creatividad, intuición, lo que ha permitido elevar su potencial profesional (Macías y Torres, 2016). Al respecto, el consumo de literatura para un comunicador debería auspiciarse en todos los ámbitos de su vida puesto que aporta al desarrollo integral de su intelecto, mejora sus actitudes analíticas, potencia su comprensión lectora, desarrolla su objetividad y estimula la generación activa de propuestas.

Por otra parte, la creación de textos creativos y literarios instituye nuevos sentidos de fidelización de las audiencias, lo que evidencia la buena recepción del público hacia contenidos especializados, a modo de menú de selección según los gustos y afinidades de cada lector, una dinámica multitasking congruente con las exigencias actuales de la Sociedad del Conocimiento.

\section{Periodismo literario}

\section{- Antecedentes}

El periodismo y la literatura entrelazan sus géneros y formatos entre sí debido a que comparten un mismo instrumento de trabajo como es la palabra. Ya lo dijo, Camilo José Cela cuando manifestó que todos los géneros literarios y periodísticos podían ser utilizados por un mismo escritor, puesto que tienen en común la herramienta de la lengua" (Hermoso, 2017).

Conforme ha ido evolucionando el periodismo en los últimos años se han suscitado pequeñas diferencias que distinguen un género del otro, una de ellas ha sido la técnica. En palabras de Camilo José Cela (Hermoso, 2017): "la técnica es como un andamiaje, se va adivinando, se va poniendo cosas en cada momento".

En la actualidad, comenta Muñoz Prieto (2016), sigue abierto el debate sobre dónde se sitúan los límites entre el periodismo y la literatura al considerar géneros como la crónica, el reportaje y la entrevista que ofrecen múltiples posibilidades de creación literaria.

Los géneros de opinión, en particular la columna y el artículo, proporcionan libertad plena no solo en concesiones estilísticas, sino en temas altamente sociales que despiertan la sensibilidad lectora, pues el periodista narra sucesos no solo de forma objetiva, sino también contextualizados mediante un análisis interpretativo (López Hidalgo, 1996).

Al hablar de la relación periodismo y literatura damos cabida a un debate extenso sobre las fronteras que dividen ambos campos. Para algunos teóricos, "la combinación del periodismo con la literatura sirve para humanizar una noticia y 
da lugar a un periodismo informativo híbrido, compuesto por elementos literarios” (Fernández Parratt, 2005).

Mientras que el periodismo apela al sentido estricto de la información y ofrece noticias veraces y objetivas para un público amplio, la literatura, en cambio, se caracteriza por el uso estético de la palabra dirigida a un público selecto. Al respecto, no es lo mismo escribir para periódicos que escribir una novela o relato. En todo caso, los textos tienen en común el hecho de que estimulan y entretienen a la audiencia en cuanto a nuevas formas de consumo cultural y gestión del ocio (Sánchez Vega, 2015).

En este escenario, el lector que lee periódicos busca encontrar noticias verdaderas y actuales, mientras que el lector que ojea obras literarias lee por pasión, sin necesidad de hallar primicias. Asimismo, abundan periodistas quienes, a pesar de su profesión de comunicadores, escriben textos de ficción. Tal y como se observa, periodismo y literatura se conjugan en la creación de trabajos periodísticos de calidad, en los cuales el periodista muestra su voz como autor y apela a recursos lingüísticos propios del campo literario.

A criterio de Yanes (2007), "hay textos que son periodismo porque en ellos prevalece la actualidad, el interés y la comunicabilidad, escritos con el propósito de informar, orientar o distraer, pero también son literatura porque contienen algo más que comunicación, interés y actualidad”.

Por ejemplo, las crónicas, los reportajes y las entrevistas son géneros pioneros en el uso del periodismo literario, los cuales exhiben valores artísticos sin renunciar a su función informativa. Para Fernández Parratt (2005), "es innegable que el periodismo y la literatura se sirven mutuamente, dándose así una tendencia a la interdisciplinariedad, cuyos textos evidencian la finalidad, el compromiso con la realidad y la veracidad".

\section{- Definición}

El periodismo literario goza de gran reconocimiento en la actualidad ya que ha permitido la creación de nuevos patrones culturales para fomentar la lectoescritura y así enfrentar la competencia mediática existente. Igualmente, son muchos los escritores que están incursionando en prensa, utilizando técnicas propias del periodismo de investigación, dando como resultado trabajos de calidad, en su punto estilístico más alto (Sánchez Vega, 2015).

Tal y como explica Yanes (2007), "se habla de un periodismo literario, cuando el género predominante es el periodístico secundado por la literatura, o bien, si se toma a la inversa, lo literario predomina ante lo periodístico”. La coincidencia fundamental entre periodismo y literatura radica en utilizar la palabra como utensilio de trabajo y la frase como vehículo de pensamiento. Como advierte Aguilera (1992), "el periodista debe ser literato, un literato de cierta y determinada clase".

Por su parte Sánchez Vega (2015) considera que la reinvención del periodismo apela al formato literario a fin de dar mayor emotividad a los textos, introdu- 
ciendo así nuevos elementos de carácter estilístico y un lenguaje gramaticalmente armónico. Es más, la crisis de verosimilitud del lenguaje periodístico empujó a sus profesionales a la experimentación con recursos propios de la narración ficcional.

En el buen periodismo literario se combina de forma magistral la experiencia periodística y el talento literario. Y es que la estrecha relación con la literatura constituye el viaje de inicio del comunicador en un encuentro subjetivo por apropiarse de los significados y sentidos de los hechos que lo rodean (Campbell, 2016).

El periodismo literario investiga, organiza y reporta historias reales, detalladas y envolventes, consideradas de conocimiento público, las cuales merecen ser discutidas e interpretadas en el seno de la sociedad en general. Por lo tanto, este género cumple una función social (Trindade \& Inácio, 2017).

A diferencia de otros géneros, el periodismo literario se considera un género más humanista e interpretativo que otros y, en consecuencia, más comprometido con la audiencia. Pauly (2011) advierte que este género aspira al cumplimiento de objetivos sociales y a una comprensión empática con su público.

No obstante, aún no ha encontrado una forma totalmente satisfactoria de lograr este propósito, ya que mantiene una visión privilegiada pero individual; es decir, es más subjetiva pues concentra su análisis en la voz del autor por encima de la voz de las fuentes. Por su parte, Carey (citado en Sims y Kramer, 1995) describe al periodismo literario como una forma imaginativa a través de la cual cada democracia se habla a sí misma de sí misma; en otras palabras, constituye un ejercicio reflexivo y de autoevaluación.

Al mismo tiempo, autores como Sims y Kramer (1995) elogian la voz liberadora del periodismo literario que encuentra la verdad en los detalles de la vida real y de la esfera cotidiana. Este género cree en el poder de las historias, en la llamada narración de historias y en la veracidad de los hechos contextualizados.

Para Gillespie (2012), el periodismo literario permite que la experiencia humana se revele de una manera más cautivadora y convincente, lo que conduce a su lectura a gran escala. Por tanto, su principal objetivo es fomentar un mayor interés y participación del público en los asuntos de actualidad.

Además de ello, este género permite una mayor conexión del autor con el lector y juega un papel relevante en la vida pública al construir perfiles en los cuales se da mayor humanización a la información, pues se exponen elementos contextuales y descriptivos que exceden el conocimiento superficial de las noticias.

El periodismo literario declara el entendimiento intercultural y el progreso humano en sus más altas metas, siendo el conocimiento y la comprensión de las diferentes culturas uno de sus propósitos, lo que deriva en piezas textuales con valores culturales simbólicos significativos (Trindale, 2012; Berning, 2011; Morton, 2014).

Por ello, "representar bien" se basa en "conocer bien" en el periodismo literario (Morton, 2014). Reconocer que los hechos recogidos, en circunstancias culturalmente específicas, asumen diferentes significados, conduce a una mayor integridad del conocimiento, la verdad y la representación ética. En este sentido, el periodismo 
literario describe los sentimientos y emociones de los individuos y, por lo tanto, se considera más subjetivo. Como resultado, surge una fuerte crítica en su contra: la falta de objetividad (Helliker, 2013).

El periodismo literario "es un nicho especial del periodismo literario estadounidense” que transpone técnicas y procedimientos de la narrativa literaria a la redacción de noticias, rompiendo las barreras tradicionales entre el periodismo y la literatura. Incluso, el periodismo literario puede ser la solución a la actual crisis periodística, ya que utiliza una escritura atractiva que atrae la atención de cualquier lector (Trindade e Inácio, 2017).

En los periódicos en línea son los textos más largos los que reciben más comentarios, lo que demuestra que los individuos están dispuestos a leer textos densos siempre y cuando estén bien escritos y sean atractivos. Por ello, se considera que la salvación del periodismo radica en transmitir información con buenas historias, capaces de despertar emoción en el lector, transmitiendo el mensaje de una manera más efectiva.

\section{- Procedimientos de escritura y narración empleados en las revistas de periodismo literario}

El periodismo literario rescata las historias vivenciales y huye a la narrativa de lo espectacular. En su escritura se define la mirada subjetiva del autor, configurando así un relato periodístico caracterizado por la hibridez y la búsqueda permanente de sentido. Para Hernández Bossio (2007) y Wolfe (1976), el periodismo literario apela a:

- Recreación de escenas.

- Construcción de diálogos.

- Configuración del tipo de narrador.

- Uso del tiempo en el texto periodístico-literario.

Tal y como ser aprecia, los mecanismos de construcción de textos periodísticos aplicando técnicas de escritura creativa y especializada son amplios. El único fin que se persigue es dotar al contenido de una forma estéticamente atractiva para su lectura.

\section{- La configuración del tipo de narrador}

En el periodismo literario se adoptan recursos propios de la ficción para contar una historia real y montar una estrategia narrativa atractiva. A criterio de Chatman (1990), al relatarse una percepción se presupone un acto de observación con un punto de vista independiente, hablamos entonces de cronista y de narrador.

Por ello, es clave precisar que en el relato periodístico el autor es el cronista, quien vive en el mundo real, mientras que el narrador es la figura que construye el cronista para contar su historia. Al respecto, Genette (1989) propuso la siguiente clasificación de narradores:

- Narrador autodiegético: es un narrador visible que participa en la historia 
como protagonista y se sitúa en un instante posterior a ella. El empleo de este tipo de narrador otorga una relación interesante entre el tiempo de la historia y el tiempo de la enunciación, lo que dota de fuerza al texto. El narrador cuenta la historia en primera persona como sucede en las autobiografías o en un libro de memorias.

- Narrador homodiegético: es un narrador visible que participa en la historia a la vez que la narra. Su relato puede ser a modo de testimonio. Cuenta la historia de otro, pero a través de su perspectiva, como testigo de los hechos. En la actualidad, es el tipo de voz narrativa más utilizada por los cronistas en revistas especializadas.

- Narrador heterodiegético: es un narrador visible que contempla la historia desde fuera sin participar como actante en la misma. Se caracteriza por el empleo de la tercera persona. Es uno de los niveles más empleados en el periodismo literario.

La configuración del tipo de narrador permite analizar la actitud del autor hacia los personajes, así como la del narrador hacia el objeto de la narración. En un relato periodístico, un lector aprecia la sensación que le brinda el autor de estar allí y ser un testigo privilegiado de la historia (Benavides, 2016).

A criterio de Herrscher (2012), el periodismo literario es capaz de hacer algo más que transmitir la voz del narrador, porque puede llevarnos a las voces, las lógicas, las sensibilidades y los puntos de vista de los otros, de los protagonistas o de los personajes de un hecho periodístico.

El punto de vista se encuentra relacionado con el tipo de narrador que el periodista decide utilizar en la historia. Una de las clasificaciones sobre este aspecto es la que brinda Friedman (1975) a continuación:

- Omnisciencia editorial: el narrador se inmiscuye en la historia.

- Omnisciencia neutral: el narrador utiliza la tercera persona de modo impersonal, no interviene directamente.

- El yo como testigo: un personaje narra en primera persona, apenas conoce los pensamientos de los demás personajes.

- El yo como protagonista: también llamado narrador protagonista, habla de sus pensamientos, etc.

- Omnisciencia multi-selectiva: la historia llega directamente a través de la conciencia de los personajes, no hay narrador.

- Omnisciencia selectiva: el punto de vista gira en torno a un único personaje.

- Modo dramático: se suprime el narrador. El lector debe deducir lo que piensan los personajes por sus palabras y gestos. Se busca objetividad absoluta.

- Cámara: se intenta presentar una historia tal como lo haría una cámara fotográfica, lo que dota a la historia de gran riqueza narrativa.

Autores como Guillén (1985) sostienen que en el acto de creación el autor tam- 
bién se hace a sí mismo, se autoinfluye, se crea, se pregunta y se cuestiona hasta qué punto influye en su vida lo que él mismo ha escrito. En otras palabras, la actividad del autor se percibe en la forma en que compone y estructura su obra.

La figura del narrador se caracteriza por contar con una insaciable curiosidad, que sabe averiguar y narrar las emociones aflictivas, los deseos, rencores o frustraciones de los protagonistas-personajes de su historia. Asimismo, quien narra en el periodismo literario tiene voz propia, impone su rasgo personal, deja su huella en la historia, impregna en el texto su personalidad e incluso transmite sus dudas y certezas (Benavides, 2016).

La voz narrativa del periodista literario adquiere un tono personal y raya en lo intimista, pero no se inventa los hechos, sino que brinda su interpretación desde el lugar donde mira. A veces, asume la voz de una persona en particular, otras veces es visible y adquiere el tono de la primera persona, inmiscuyéndose como personaje en la historia, ocasionalmente permanece al pie del relato como narrador omnisciente y emite valoraciones sobre lo que ha presenciado. En síntesis, la configuración del tipo de narrador es un procedimiento esencial del periodismo literario.

\section{- El uso del tiempo en el relato periodístico-literario}

Para Genette (1989), el tiempo en la historia narrada tiene un orden compuesto por anacronías, las cuales constituyen toda alteración a la estructura del relato. El alcance de una anacronía es el salto temporal que esta supone; es decir, la distancia que media entre el momento en que se encuentra el relato primero y al punto al que se retrotrae. Las anacronías pueden ser:

- Analepsis o retrospecciones temporales: saltos al pasado, se observa principalmente en la crónica.

- Prolepsis o anticipaciones temporales: cuenta o evoca por adelantado un acontecimiento posterior al punto de la historia donde nos encontramos.

Según Genette (1989), un relato puede prescindir de anacronías, pero no puede existir sin efectos de ritmo; es decir, sin pausa, escena o sumario. Bajtín (1989) definió esta idea con el concepto de cronotopo, que refiere a la posibilidad de ver el tiempo a través del espacio.

En el cronotopo literario tiene lugar la unión de elementos espaciales y temporales en un todo inteligible y concreto. En periodismo, la figura del cronotopo le da forma al argumento del relato, pues en este se concentran los acontecimientos argumentales, sucesos que se pueden narrar porque brindan indicaciones exactas acerca del lugar y tiempo de su realización (Bajtín, 1989).

En este contexto, no existe espacio ni tiempo por separado, pues ambos elementos se complementan simultáneamente. Según Vázquez Medel (2001), "no hay espacio sin tiempo, ni tiempo sin espacio por más que nuestras operaciones separadoras insistan en ello.

La noción del cronotopo es un concepto que insiste en ser vivido, vivenciado y 
experimentado". El cronotopo literario es el campo principal para la representación de los acontecimientos en imágenes, lo que es posible debido a la concentración y concreción de las señas del tiempo en determinados sectores del espacio.

Uno de los autores que trabaja la categoría tiempo es Ricoeur (1995) para quien la narración alude a la comprensión temporal de la experiencia humana y al problema de la identidad. En el caso del periodismo literario, el cronista transmite una vivencia del tiempo en que se mueven los personajes, brindando un modo artístico al tiempo en su discurso, mientras que el lector asume estos postulados partiendo de su propia experiencia.

Como se ha analizado, el periodismo literario destaca las marcas en primera persona, el uso de recursos estilísticos, la aplicación de figuras de estilo y el empleo de descripción/caracterización de situaciones, espacios y personajes. Incluso, el periodista se convierte en uno de los protagonistas, describiendo los hechos en primera persona, convirtiéndose en el narrador participante, apelando al lenguaje directo y a las elocuciones de sus personajes (Benavides, 2016).

\section{Metodología}

Para esta investigación se utilizó una metodología cualitativa, aplicando para ello la técnica de la revisión bibliográfica y la entrevista a docentes, profesionales y periodistas, a quienes se les consultó sobre la importancia de la escritura creativa y la creación literaria en el ámbito de la comunicación. Los entrevistados seleccionados tienen amplia trayectoria académica, motivo por el cual fueron escogidos como fuentes de información. Las preguntas se establecieron en torno a tres ejes de discusión, segmentados así:

- Según su opinión, ¿cuál es la importancia de la escritura creativa y la creación literaria en la formación académica?

- ¿Cree que la lectoescritura es importante en la formación académica de un comunicador?

- ¿Cree que es fundamental la lectoescritura en la formación de un comunicador?

\section{Resultados}

Para los entrevistados hay que partir de un hecho. Y es que en Ecuador no hay una universidad que esté potenciando el tema de la escritura creativa, puesto que no existe una especialidad o fuentes de trabajo en esta área, ni siquiera en el propio periodismo. Por tanto, este tema es una asignatura pendiente en nuestro país; y, por el contrario, muy dinámica en Argentina, Chile y México, donde se hacen programas 
emblemáticos en escritura creativa, con mayores insumos y financiamiento desde las instituciones del Estado.

A más de ello, los entrevistados consideran que la creación literaria es importante para la formación del comunicador, ya que el periodista debe narrar temas palpables de manera ingeniosa, de forma agradable, pues un hecho social no solo puede ser tratado de modo noticioso, sino también de modo literario.

Al hablar de escritura creativa, se habla de la posibilidad de que el periodista proponga textos diferentes, alternativos y alterativos de aquello conocido. Los profesionales de la comunicación deben ser versátiles para adaptar sus textos, teniendo en cuenta que esta disciplina es de carácter híbrido y mutable. Al respecto, es evidente la existencia de nuevos lenguajes, nuevas narrativas y en este sentido el periodista debe generar nuevas lógicas al momento de escribir.

En prensa escrita, por ejemplo, la creatividad es importante para visualizar un tema y para el desarrollo narrativo de una historia, así el lector, emocionalmente, se empieza a fijar en cómo el periodista escribe. Por tanto, el aporte de la literatura va en el sentido de la formación personal. Gracias a lo literario, un periodista amplía el conocimiento de su sensibilidad, de su humanismo. En otras palabras, el ejercicio de la lectura permite al ser humano verse reflejado a sí mismo.

A criterio de los entrevistados, los comunicadores sociales nunca deben prescindir de los conocimientos y de aquellas bases teóricas que les permitan enfocarse, de forma contextualizada, en la realidad de los hechos. Por ello, tienen que demostrar conocimientos sobre teoría literaria, cultura general, arte y literatura, solo así lograrían un acercamiento más próximo a la realidad social. Y es que, desde su postura, la literatura es una manera de decir verdades que van más allá de lo real, de lo que observamos de la cotidianidad.

Los entrevistados consideran que la comunicación es un campo de trabajo para la escritura no solo académica, sino también relacionada a la pedagogía de la sensibilidad, pedagogía de la ternura, en la que sus profesionales sean capaces de crear piezas textualez creativas, y al mismo tiempo sensibles. Desde su perspectiva, los comunicadores deberían pensar la literatura como una metodología que puede aportar conocimientos culturales y nuevas formas de establecer conversaciones con el otro.

De alguna forma piensan que, si el periodismo es contar historias, la literatura es construir historias con metáforas, con ficciones, es dibujar imágenes con palabras. Es más, la escritura despierta los sentidos de percepción y por ello, ayuda a tener una opinión crítica en cuanto a lo que sucede alrededor, entonces los comunicadores necesitan formación en escritura creativa.

Desde su juicio de valor, un comunicador que no conozca su contexto inmediato e histórico, es un comunicador incompleto. Este comunicador quizás podría hablar de actualidad y podría repetir las noticias que salen de las agencias, que ya están fabricadas y a veces solo hay que leer, pero carecería de muchísima capacidad 
de analizar, de sintetizar, de extraer el meollo del asunto, de comunicar a la gente común lo que está entrelíneas, de lo que ocurre en verdad.

Y es que el comunicador debería ser la persona más informada, que vaya más allá del suceso e interprete a cabalidad la información obtenida, es el que debería ayudarnos a todos los demás a enfocar nuestro interés en asuntos relevantes para el bien común de la humanidad, para despertar la sensibilidad lectora.

Tal y como refieren los entrevistados, en la actualidad, tan informados estamos, pero al mismo tiempo tan insensibles estamos. Ya no nos sorprende nada, pues todo es posible encontrar en el río de la información digital. Como respuesta a este malestar moral, un comunicador tiene que cumplir otro tipo de rol y es el de ser indispensable para su sociedad.

La literatura periodística despierta una realidad escrita desde el cuerpo, desde el sufrimiento, desde la mirada del otro, no desde la individualidad; además es arrasadora en cuanto a la forma, es una literatura que desbarata al mundo actual, constituye una perspectiva nueva y revitalizada. Enfrentarse a ese tipo de lecturas en donde todas las visiones particulares y estrechas se rompen, se resquebrajan y la mentalidad del lector se abre para dar cabida a otro, a un otro diferente, a un otro que sufre, es significativo para cualquier profesional.

Un comunicador literario va a tener una visión distinta del mundo, va a tener juicios de valor de lo que ocurre en los gobiernos a su alrededor, un juicio totalmente diferente a lo que estamos acostumbrados a escuchar. Entonces, el periodismo literario es un arma poderosísima de transformación y el lector más experimentado va creciendo en ese nivel de transformación. Y es que una verdadera literatura siempre tendrá un efecto transformador y terminará tocando la estructura misma del lector.

De acuerdo con los entrevistados, la literatura es una de las ciencias más sensibles que tiene el ser humano y por ende hay que trabajar muchísimo con nuevos profesionales en comunicación para que practiquen el ejericio de la literatura como una forma de sensibilizar su trabajo y transmitir su labor con mayor humanismo.

En otras palabras, la literatura humaniza y para lograr comunicadores con una vocación humanista se deberían implementar talleres de escritura creativa y de creación literaria de forma permanente, puesto que, si un comunicador no lee, es como un carnicero que no le gusta el olor de la carne, como un doctor que no tolera la sangre. No podemos hablar de un comunicador que no lea porque dentro de su lógica profesional la lectoescritura es parte intrínseca de su formación. La lectura es el único camino para que el comunicador llegue a perfeccionarse como tal y haga honor a su nombre.

A juicio de los entrevistados, los beneficios de la escritura creativa son múltiples. Por ejemplo, brinda facilidad de escribir, argumentar y producir un contenido especializado. Por el contrario, si el comunicador no lee ni ejerce la escritura creativa producirá textos superficiales y descontextualizados. Según su testimonio, la academia está para formar, pero el hábito literario debe nacer del periodista, ya que 
el periodismo literario se logra con experiencia, talento, disciplina y vocación, sin dejar de lado el rol protagónico de la lectura.

\section{Conclusiones}

Al término de la investigación se evidencia un cambio signiticativo en el ejercicio profesional de la comunicación, por ello hay que generar nuevas maneras de acercamiento con el público a través de la propuesta de productos comunicacionales alternativos e innovadores, que combinen la escritura creativa y la creación literaria, lo que daría como resultado una renovación de estilo, formatos, narrativas y modos de contar las historias.

Tal y como escribe Tusa (2016), "es necesario apostar hacia el humanismo como forma de vida, como vocación de servicio social" y eso justamente lo encontramos en la escritura y en el periodismo literario, género que dota de sensibilidad y humanismo a los productos comunicacionales adscritos a su formato.

Con la aplicación de entrevistas a docentes en comunicación y escritores se confirma la importancia de la escritura creativa y la literatura para profesionales en comunicación, debido a los beneficios que brinda en el tratamiento de la información en cuanto al uso de técnicas que aportan a la construcción formal del género periodismo literario.

Asimismo, cabe mencionar que las características intrínsecas del periodismo literario señaladas por los entrevistados fueron: profundidad, mayor investigación en el campo, observación directa y experiencia de los acontecimientos para hacer un retrato confiable de los hechos; escritura densa y elaborada, diálogo, uso de figuras de estilo, mayor narrativa de los detalles, entre otros.

\section{Recomendaciones}

- Después del análisis realizado se recomienda a la academia universitaria la creación de nuevos perfiles de egreso, transversales e interdisciplinarios, que tengan en cuenta las habilidades de lectoescritura de los futuros profesionales en el área periodística. Estos programas académicos deben ser integrales, híbridos y congruentes con el tiempo y el espacio contextual de nuestra sociedad.

- Reforzar el interés de los comunicadores en cuanto a la escritura literaria, a través de la formación y la capacitación continua en géneros periodísticos como crónica, perfil y reportaje, los cuales permiten el desarrollo a profundidad de variadas técnicas narrativas. 
- Considerar la creación de talleres o clubes de lectura y escritura de manera transversal al currículo, en horarios extraclase, para que los futuros profesionales de la Comunicación tengan un espacio adecuado para desarrollar sus destrezas lectoras y sus habilidades de escritura. 


\section{Referencias}

Aguilera, O. (1992). La literatura en el periodismo: $y$ otros estudios en torno a la libertad y el mensaje informativo. Madrid: Paraninfo.

Angulo, V. \& José, M. (2017). La formación de los comunicadores sociales en la Universidad Estatal de Bolivar y su relación con los requerimientos de la Comunicación Digital. Ambato: Universidad Técnica de Ambato.

Bajtín, M. (1989). Teoría y estética de la novela. México D.F.: Siglo XXI.

Benavides, J. (2016). Procedimientos narrativos, procesos creativos y de producción de los cronistas ecuatorianos en las revistas de periodismo literario. Un estudio de los casos Mundo Diners, SoHo y Gatopardo. La Plata: Universidad La Plata. Disponible en: https://bit.ly/2OiGbGP

Berman, M. \& Semilla, M. (2017). Los nuevos ejercicios de la profesión del comunicador social en el escenario actual. Ambato: Universidad Técnica de Ambato.

Berning, N. (2011). Toward a Critical Ethical Narratology for Literary Reportages: Analyzing the Story Ethics of Alexandra Fuller's Scribbling the Cat. Interferences litte'raires/Literaire Interferenties, 7, 189 -221.

Campbell, F. (2016). Periodismo escrito. Madrid: Fondo Editorial Tierra Adentro.

Campaña de Lectura (2019). Campaña de lectura Eugenio Espejo. Quito. Disponible en: https://bit.ly/2qD890p

Chatman, S. (1990). Historia y discurso: la estructura narrativa en la novela y en el cine. Madrid: Taurus.

de Agar, R. \& López, C. (2018). Programa LEO para la iniciación a la lectoescritura. Evaluación inicial de los cuentos. Boletín de Estudios e Investigación, 18, 147-177.

Delgado, M. (2014). Deja volar tu imaginación: recursos para fomentar la escritura creativa en clase de E/LE. Foro de Profesores, 10, 54-61.

Fernández Parratt, S. (2005). Periodismo y literatura: una contribución a la delimitación de la frontera. Estudios sobre el mensaje periodístico, 12, 275-284.

Friedman, N. (1975). Aspectos de la novela moderna. El punto de vista en la ficción: el desarrollo de un concepto crítico. Revista Els Marges, 3, 39-60.

García Márquez, G. (1982). El Mejor oficio del mundo. Madrid: diario El País. Disponible en: https://bit.ly/2BjxLXm

García Márquez, G. (2014). Yo no vengo a decir un discurso. Madrid: De Bolsillo.

Genette, G. (1989). Figuras III. Barcelona: Lumen. 
Gillespie, B. (2012). Building bridges between literary journalism and alternative ethnographic forms: opportunities and challenges. Literary Journalism Studies, 4(2), 67-80.

Guillén, C. (1985). Entre lo uno y lo diverso. Introducción a la literatura comparada. Barcelona: Tusquets.

Gonzales, M., Rodríguez, C. \& Rivera, D. (2016, June). Digital journalist Ecuador profile: Competencies and skills. In Information Systems and Technologies, CISTI, 1-5.

Helliker, K. (2013, Feb. 8). Capote Classic 'In Cold Blood' Tainted by Long-Lost Files. Disponible en: The Wall Street Journal.

Hermoso, B. (2017). Cela, la literatura y los periódicos. Diario El País. Disponible en: https://bit.ly/32a5LjS

Hernández Bossio, A.B. (1990). Ramos Sucre: la voz de la retórica. Caracas: Monte Ávila Editores.

Herrscher, R. (2012). Periodismo narrativo. Cómo contar la realidad con las armas de la literatura. Barcelona: Universidad de Barcelona.

López Hidalgo, A. (1996). Las columnas del periódico. Madrid: Ediciones Libertarias/Prodhufi.

Morton, L. (2014). Not my people. The epistemological complexities of knowing and representing other cultures in literary journalism. Journalism Studies, 15(6), 774-788.

Muñoz Prieto, A. (2016). Juan José Millás: Entre el periodismo y la literatura. La Laguna: Universidad de La Laguna.

Osca, J., Díaz, M. \& Hernández, J. (2015). Taller de Escritura Creativa para el desarrollo de la Competencia Literaria en Brasil. Didáctica: Lengua y Literatura, 27, 97.

Pauly, J. (2011). Literary Journalism and the Drama of Civic Life: Keynote address, IALJS, Brussels, Belgium May 13, 2011. Literary Journalism Studies, 3(2), 73-82.

Ricoeur, P. (1995). Tiempo y narración: Configuración del tiempo en el relato histórico. México D.F.: Siglo XXI Editores.

Sánchez Vega, C. (2015). El periodismo clásico frente al Nuevo Periodismo. Correspondencias er Análisis, 5, 187-195.

Sánchez Ortiz, J. \& Brito Guerra, N. (2015). Desarrollo de competencias comunicativas mediante la lectura crítica, escritura creativa y expresión oral. Universidad Autónoma del Caribe.

Sims, N. (1984). The literary journalists. New York: Ballantine Books. 
Sims, N. \& Kramer, M. E. (1995). Literary Journalism. A New Collection of the Best American Nonfiction. New York: Ballantine Books.

Solís, L. (2014). Carrera de resistencias: La escritura creativa en la ficción televisiva peruana narrada por 5 guionistas. Lima.

Trindade, A. (2012). Lush Words in the Drought: The Literary Journalism of Pedro Cardoso. In Global Literary Journalism. Exploring the Journalistic Imagination. New York: Peter Lang Publishers.

Trindade, A. \& Inácio, R. (2017). Literary journalism, human rights and integration: a portuguese instance. Cuadernos.info, 40, 235-249.

Tusa, F. (2016). El Humanismo ético del siglo XXI a través del pensamiento de Ryszard Kapuscinski. Revista Historia y Comunicación Social, 21 (2), 363-377.

Wolfe, T. (1976). El Nuevo Periodismo. Barcelona: Anagrama.

Vázquez Medel, M.A. (2002). El simbolismo narrativo. Ínsula: Revista de Letras y Ciencias Humanas, 665, 9-11.

Vivaldi Martín, G. (1974). Curso de redacción. Teoría y práctica de la composición y del estilo. Madrid: Editorial Paraninfo.

Yanes, R. (2007). La crónica, un género del periodismo literario equidistante entre información y la interpretación. Disponible en http://www.ucm.es/info/especulo/ numerp $32 /$ cronica.html 
Universidad Técnica de Machala

Ediciones UTMACH

Primera edición en español 2020

PDF interactivo 


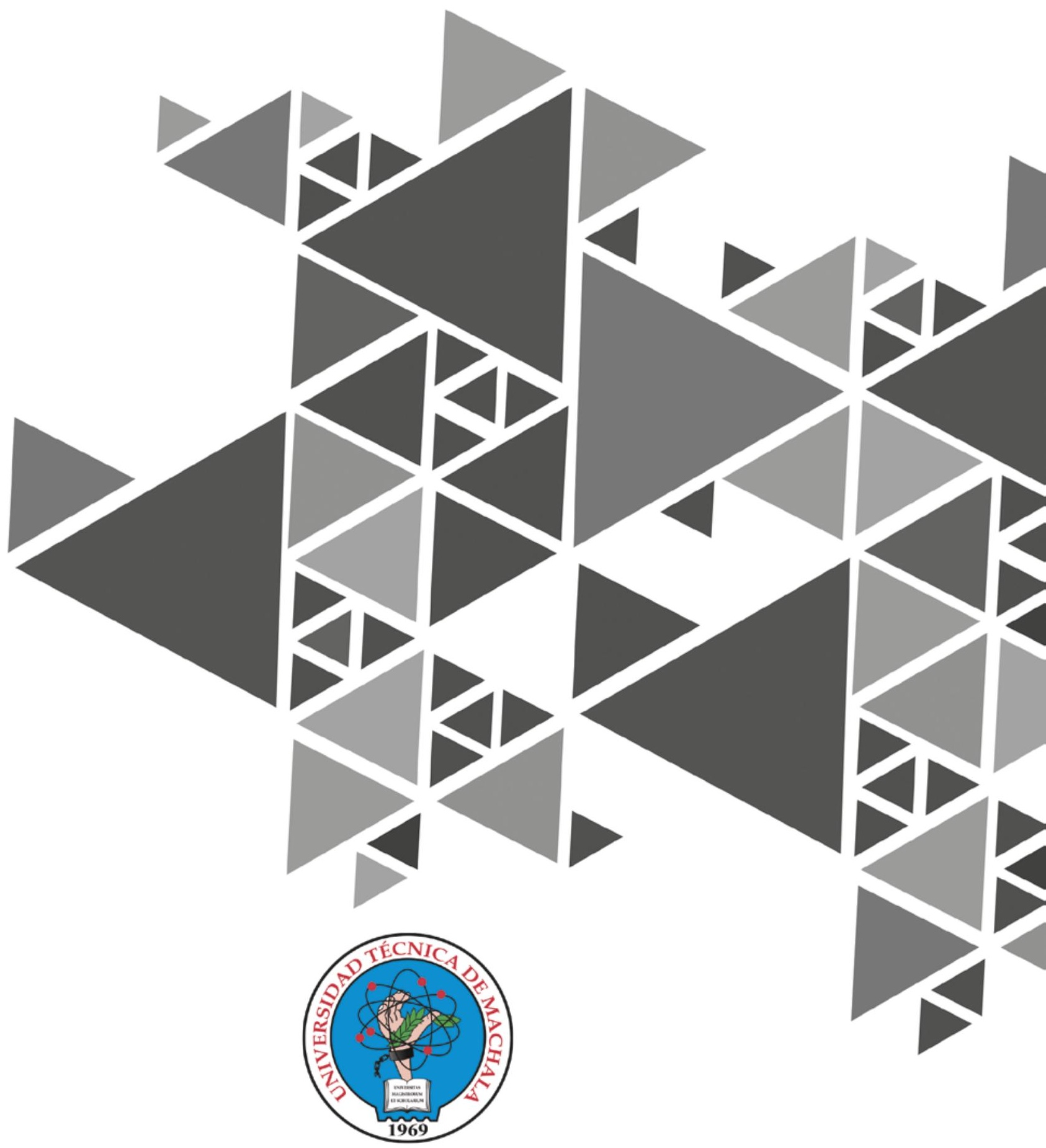

Universidad Técnica de Machala

Dirección de Investigación

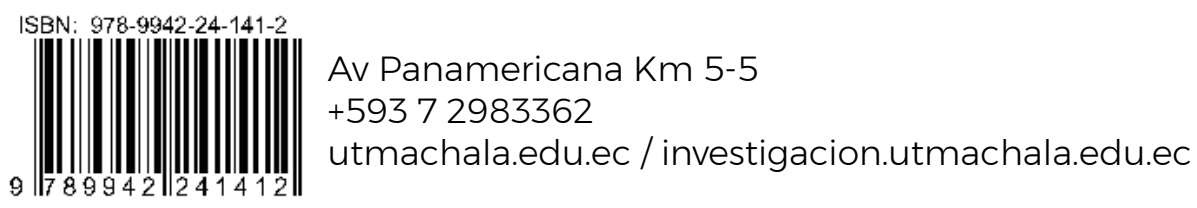

